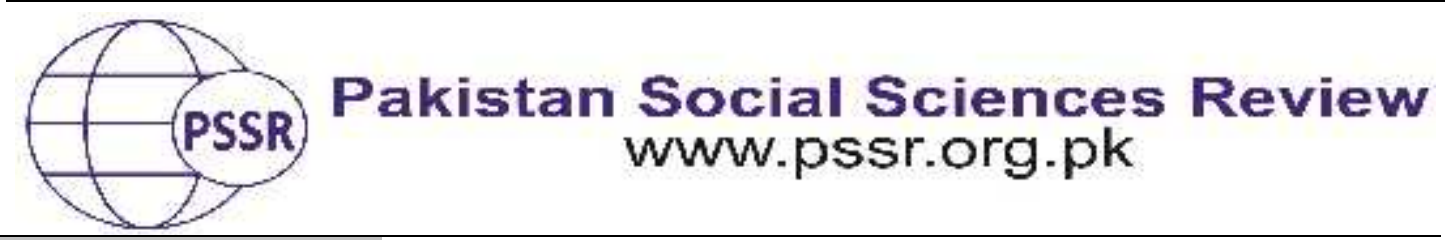

RESEARCH PAPER

\title{
A Study on Pre-and Post-Competition State Anxiety among the Athletes
}

\author{
Mehwish Manzoor ${ }^{1}$ Rehana Parveen 2 Saira Yaqoob ${ }^{3}$
}

1. Visiting Lecturer, Department of Physical Education, University of Narowal, Punjab, Pakistan.

2. Govt..E/Shasti Waladullewala Darya Khan, Pakistan

3. Gomal University D.I. Khan, KPK, Pakistan

\begin{tabular}{|c|c|}
\hline & \\
\hline & \multirow{15}{*}{$\begin{array}{l}\text { This study investigates and evaluates before and after } \\
\text { competitive anxiety, self-confidence, and performance of the } \\
\text { athletes. The Cognitive State Anxiety Inventory-2 was } \\
\text { administered to collect data from } 73 \text { athletes, both men and } \\
\text { women, before and after the competition. The paired t-test was } \\
\text { used to find the significant difference between the pre and post } \\
\text { competition. Results showed that the levels of cognitive } \\
\text { condition of anxiety before the competition were low as } \\
\text { compared after the competition and the levels of somatic state } \\
\text { anxiety before the competition was high as compared after the } \\
\text { competition, whereas the levels of self-confidence before the } \\
\text { competition were high as compared after the competition. This } \\
\text { study concludes that the levels of cognitive state anxiety } \\
\text { increase after the competition as athletes could not perform } \\
\text { according to the performance expectations; on the contrary, the } \\
\text { levels of somatic anxiety decrease as there was no pressure of } \\
\text { performance on the athletes after the competition and the levels } \\
\text { of self-confidence decrease after the competition as athletes } \\
\text { could not reach their desired performance levels. }\end{array}$} \\
\hline & \\
\hline & \\
\hline & \\
\hline & \\
\hline & \\
\hline & \\
\hline & \\
\hline & \\
\hline & \\
\hline & \\
\hline & \\
\hline & \\
\hline & \\
\hline & \\
\hline
\end{tabular}

\section{Introduction}

To begin with, affect is a generic term used to describe emotions, feelings, and moods. Emotion is a situation specific affective response to the environment. (Lazarus (2000a) defined emotion as "an organized psycho physiological reaction to on-going relationships with the environment, most often, but not always interpersonal or social." Lazarus further identified 15 specific emotions and core themes associated with each emotion. The emotion of anxiety is closely related to Han (Selye's,2016)concept of stress (pronounced "sale-ye") defined stress as the "non-specific response to the body to any demand made on it." When aroused, the body is under stress regardless of whether the cause is something negative such as anger or something positive like joy. 
As clinicians, we cannot underestimate the extent to which individuals who show high levels of negative affectivity generally manifest elevated levels of distress, anxiety, dissatisfaction, and a tendency toward focusing on the unpleasant aspects of themselves, other people, the world/life, and the future (Gross \& Jazaieri, 2014; Jeronimus, 2014). Regular physical activity increases the skill levels \& confidence level and decrease the Stress level \& state Anxiety.

\section{Cognitive and Somatic Anxiety}

Distinguished between two aspects of anxiety when we are anxious, we experience the physiological changes associated with high arousal, including increased heart rate and blood pressure, "butterflies" in the stomach, faster breathing, and flushed face. These effects are similar (though not identical) to the physiological effects of excitement and anger. We call the experience of physiological changes associated with anxiety somatic anxiety (from the Greek soma meaning body). We can measure somatic anxiety directly by physiological means, or indirectly by self-rating inventories. Direct physiological measures include urinalysis, galvanic skin response, and blood pressure testing. Elevated levels of certain hormones released when we are anxious (such as adrenalin), which can be detected in urine. We also tend to sweat more when anxious. There are two major problems with the physiological measures of anxiety. First, as we vary quite a lot in our normal physiological levels, all individuals studied would have to have physiological measures taken over time to establish their levels with and without anxiety. Second, physiological measures require laboratory equipment and are difficult to administer in the field. Self-rating inventories can be used to measure somatic anxiety indirectly.

Self-confidence is a vital part of athletes' personalities, and others quickly recognize it in them. More important, having optimal self-confidence is probably the most critical aspect of developing a flow mindset. Most of the coaches and athletes think self-confidence means believing they will win or outperform their opponent. Self-confidence is an accumulation of one's unique achievements across many different tasks and situations, coupled with preparation for the upcoming event, which enables one to develop specific expectations of achieving future success (as in the opening quote from Michael Jordan). Self-confidence is a crucial mental skill without a healthy foundation of realistic self-confidence; your athletes will not be able to reach their true potential (Nayak, \&Chatterjee, 2013).

The physical exercise, Surprisingly, the effects of exercise may be determined relatively quickly: just eight weeks of pre-season training on body composition, physical fitness, anaerobic capacity, and isokinetic strength in collegiate taekwondo athletes in endurance gave improvements on all these parameters, as assessed by relative peak power and anaerobic capacity and angular velocity (Gaurav, V. (2011).Psychological well-being, cognitive, emotional, motor, behavioral, clinical, recuperative, epigenetic and health domains all make considerable impact upon individuals' propensity for and compliance with regular exercise and physical activity and vice versa throughout the lifespan development, (M.O.,2017) 
However, many individuals with heightened negative affectivity do not exhibit high levels of anxiety or develop anxiety disorders. Such findings have led researchers to examine the potential factors that mediate or moderate the relationship between affectivity and anxiety (Tortella, 2010).

This definition of mental health highlights emotional well-being, the capacity to live a full and creative life, and the flexibility to deal with life's inevitable challenges. Positive psychology is increasingly prominent in mental health. A holistic model of mental health generally includes concepts based on anthropological, educational, psychological, religious and sociological perspectives, as well as theoretical perspectives from personality, social, clinical, health, and developmental psychology (Sandoval \& Davis 1981).

Basically Understanding the behavior Sports psychology helps in understanding the behavior of athletes or sportsperson engaged in competitive sports. Coaches also come to know the interest, attitude toward physical activity, instincts, drives, and personality of sportsperson. Pre-performance routine, Preperformance routines refer to the actions and behaviors athletes use to prepare for a game or performance. These routines help to develop consistency and predictability for the player. This allows the muscles and mind to develop the motor skills. Selftalk refers to the thoughts and words, athletes and performers say to themselves usually in their minds. Program focuses to improve many psychological skills and offer optimal training (Macdougall, 2001) (Wann, 1998).

\section{Literature Review}

According to Bonnet, Emotion regulation and, more specifically, alexithymia are the constructs most frequently cited as playing a mediating role in the relationship between negative affectivity and anxiety. Indeed, research suggests that negative affectivity increases alexithymia (Bonnet,2012; Gaher2015; Suslow and Donges, 2017).

Sheppes defines about Even if affects and related personality dimensions have a pivotal impact on psychological distress, when we consider such links between affect and psychopathology, we also have to take into account the emotion regulation strategies that individuals activate to manage the feelings they are experiencing and to deal with distress (Sheppes,2015).

As suggested by (Bagby 1994), alexithymia can be described as a difficulty in identifying and describing feelings, as well as in distinguishing feelings from the bodily sensations of emotional arousal. Alexithymic individuals also exhibit constricted imaginative processes and externally oriented thinking (Taylor, 2000).

They are often assailed by widespread negative affect, social evasion and poor emotional relationships with other people. From a wider clinical perspective, there is strong evidence that emotion regulation is closely related to most, if not all, 
anxious and depressive disorders. A positive association between emotional regulation and anxiety has been found, in particular between alexithymia (most notably difficulties identifying and describing feelings) and anxiety (Devine, 1999; Craske, 2003).

According to Paivio about self-confidence is a vital part of athletes' personalities, and others quickly recognize it in them. More important, having optimal self-confidence is probably the most critical aspect of developing a flow mindset. [Most of the coaches and athletes think self-confidence means believing they will win or outperform their opponent. Self-confidence is an accumulation of one's unique achievements across many different tasks and situations, coupled with preparation for the upcoming event, which enables one to develop specific expectations of achieving future success (as in the opening quote from Michael Jordan). Self-confidence is a crucial mental skill without a healthy foundation of realistic self-confidence; your athletes will not be able to reach their true potential (Paivio \& McCulloch, 2004).

The link between alexithymia and psychological distress has already been explored in university students, most notably relating to the symptoms of depression and neuroticism (Morera, 2005; Liang and West, 2011).self-injurious behaviors, and interpersonal problems (Vanheule, 2007).

In exploring university students' distress, we have to consider contextual facets such as housing conditions. As clinicians, we cannot underestimate the extent to which individuals who show high levels of negative affectivity generally manifest elevated levels of distress, anxiety, dissatisfaction, and a tendency toward focusing on the unpleasant aspects of themselves, other people, the world/life, and the future (Gross and Jazaieri, 2014; Jeronimus, 2014).

We also hypothesized that alexithymia mediates the relationship between negative affectivity and anxiety. Previous research has already suggested this mediation effect, but as far as we know the model has not yet been tested on university students. In addition, since housing conditions have already been linked to anxiety by previous research, we decided to include them in our model as a moderator. Indeed, literature shows how alexithymia and negative affectivity are rarely, or only minimally, influenced by contextual variables (Mroczek \& Kolarz, 1998; Luminet, 2007).

This study sought to better understand the distress experienced by students by considering contextual facets (e.g., housing conditions) as well as stable clinical variables (e.g., negative affectivity, emotion regulation, and anxiety

\section{Material and Methods}

The Competitive State Anxiety Inventory-2 (CSAI-2) was administered to collect the data from 73 athletes, both men and women, the subjects were randomly selected for the study. An assessment of anxiety and self -confidence $24 \mathrm{~h}$ pre a 
competition may not yield the same information about one's state as when administered just 30-60 min prior before the competition and after the completion of the competition and the subjects were also told to write about their feelings before the competition, during the competition and after the competition, held at Municipal stadium, Daska Sialkot Pakistan.

\section{Results and Discussion}

Table 1

Paired samples correlations

\begin{tabular}{ccccc}
\hline & & $\mathbf{N}$ & Correlation & SIG \\
\hline Pair 1 & Before and after-test total & 73 & 0.527 & 0.05 \\
\hline
\end{tabular}

Table 2

Paired samples statistics

\begin{tabular}{cccccc}
\hline & & $\mathbf{N}$ & $\mathbf{N}$ & Standard deviation & Standard error mean \\
\hline $\begin{array}{c}\text { Pair } \\
1\end{array}$ & $\begin{array}{c}\text { Pre-test total } \\
61.6164\end{array}$ & 73 & 9.0154 & 1.0480 \\
\hline & $\begin{array}{c}\text { Post-test } \\
\text { total }\end{array}$ & 60.4383 & 73 & 10.8804 & 1.2648 \\
\hline
\end{tabular}

Results showed that the levels of cognitive state anxiety before the competition were low as compared after the competition, and the levels of somatic state anxiety before the competition were high as compared after the competition, whereas the levels of self-confidence before the competition were high as compared after the competition. The mean in the pre-test is higher as compare to post-test. Most athletes have a high level of anxiety and the level of self-confidence was also high. The levels of cognitive and somatic anxiety are almost the same, whereas their self-confidence is very high.

Anxiety, and depression, we found that the relationship between negative affectivity and both state and trait anxiety was mediated by alexithymia but housing conditions did not act as a moderator for the indirect effect of negative affectivity on state or trait anxiety through alexithymia.

\section{Conclusion}

From the analysis, it can be concluded that the levels of cognitive state anxiety increase after the completion of the competition as the athletes could not perform according to their performance expectations; on the contrary, the levels of somatic state anxiety decrease as there was no pressure of the performance on the athletes after the completion of the competition and the levels of self-confidence decrease after the completion of the competition as athletes could not reach their desired performance levels. Pre-competition and post-competition state anxiety levels were found to have an effect on both the success and failure of an athlete. 
The present study sought to gain insight into the anxiety experienced by athletes (students) while taking into account the importance of personality and clinical characteristics that have previously been widely underestimated. We found that these characteristics can be of extreme importance for developing preventative and therapeutic interventions tailored to the clinical characteristics of students, as well taking into account their living environment. 


\section{References}

Archer, T. (2015a). Physical exercise as an epigenetic factor determining behavioral outcomes. ClinExp Psych 1: 1.

Ghorbanzadeh, B. \& Bayar, P. (2013) A comparison of the pre-competition and post competition anxiety levels of Taekwando athletes. Life Sci J, 10(2), 5-10.

Horn, T. S. (2007). Advances in Sports Psychology. 3rd ed. Champaign, IL: Human Kinetic

Leunes, (2015). A Sports Psychology. 45th ed. New York: Psychology Press.

Mikolajczak, M., Menil, C., \&Luminet, O. (2007). Explaining the protective effect of trait emotional intelligence regarding occupational stress: Exploration of emotional labour processes. Journal of Research in personality, 41(5), 1107-1117.

Nayak, B., \& Chatterjee, K. (2013). Comparative study on pre-compettition anxiety between national and state level women athletes. IOSR J Sports PhysEduc, 1(2), 33-36.

Sekeroglu, M.O. (2017). Examining the pre and post-competition state anxiety levels of sportswomen of the Dutch women's volleyball national team. J Educ Train Stud, 5(13), 2898.

Singh, A., \& Gaurav, V. (2011). A study of pre-competition and post-competition anxiety level of inter-collegiate volleyball players. Int J Sports SciEng, 5(4), 237241.

Tortella-Feliu, M., Balle, M., \& Sesé, A. (2010). Relationships between negative affectivity, emotion regulation, anxiety, and depressive symptoms in adolescents as examined through structural equation modeling. Journal of Anxiety Disorders, 24(7), 686-693.

Turksoy, A., Bayansalduz, M., Altinci, E.E., \& Atikir, (2012) A. Comparision of pre and post-anxiety levels of volleyball players aged 11-14. Int J Acad Res, 4(1), 143147.

Vanheule, S., Desmet, M., Meganck, R., \&Bogaerts, S. (2007). Alexithymia and interpersonal problems. Journal of clinical psychology, 63(1), 109-117. 